\title{
Pesquisa em avaliação: algumas reflexões ${ }^{1}$
}

\section{Maria Isabel Ramalho Ortigão}

Universidade do Estado do Rio de Janeiro

isabelortigao@terra.com.br

\section{Maria José Costa dos Santos}

Universidade Federal do Ceará

mazzesantos@ufc.br

\section{Carlos Augusto Aguilar Júnior}

Universidade Federal Fluminense

carlosaugustobolivar@hotmail.com

\begin{abstract}
Resumo
Apresentam-se neste texto algumas das pesquisas desenvolvidas no âmbito do Grupo de Pesquisa Políticas de Avaliação, Desigualdades e Educação Matemática, vinculado ao Programa de Pós-Graduação em Educação (PROPEd/UERJ). O grupo envolve professores universitários, professores da educação básica, estudantes de pós-graduação (nos níveis de Doutorado e de Mestrado) e estudantes de graduação. Especificamente aqui se trata das pesquisas que tiveram o PISA - Programa Internacional de Avaliação de Estudantes - e o SAEB - Sistema Nacional de Avaliação da Educação - como foco de investigação. Apoiando-se nas recomendações teórico-metodológicas de Babbie (2005) e de Somekh e Lewin (2015), e nos estudos de cunho sociológico, o grupo pretende investigar: (a) a associação entre características dos estudantes e o desempenho em Matemática; (b) a associação entre tais características e a repetência; (c) a existência de ênfases curriculares diferenciadas em Matemática entre escolas brasileiras; (d) os sentidos atribuídos aos conceitos que estão na base da concepção do PISA. Os três primeiros objetivos citados lidam com modelos de regressão estatística. Já o quarto visa à compreensão da própria política emanada pelo PISA. Espera-se, assim, ampliar o debate curricular nos campos da Educação e da Educação Matemática e buscar uma ampla compreensão sobre as políticas de avaliação nas escolas brasileiras.
\end{abstract}

Palavras-chave: Políticas de avaliação. Currículo de Matemática. Repetência. Abordagem Qualitativa e Quantitativa.

\section{Assessment research: some reflections ${ }^{2}$}

\begin{abstract}
In this article, some of the developed researches in the Assessment Policy, Inequalities and Mathematics Education Research Group, linked to the Post-Graduate Program in Education

\footnotetext{
${ }^{1}$ Uma primeira versão, mais simplificada, deste texto foi apresentada no VIII Simpósio de Pesquisa em Educação Matemática do Estado do Rio de Janeiro - VIII SPEM, em novembro de 2016.

${ }^{2}$ A simplified first version of this text was presented at the VIII Symposium on Research in Mathematical Education of the State of Rio de Janeiro - VIII SPEM, in November, 2016.
} 
(PROPEd/UERJ) will be presented. The group involves professors, teachers, post-graduate students (Doctorate and Master) and undergraduate students. The subject here is specifically the researches which had PISA - Programme for International Student Assessment - and a SAEB - National System of Education Assessment - as focus. Based on the theoretical and methodological recommendations of Babbie (2005) and Somekh and Lewin (2015) and on sociological studies, the group intends to investigate: (a) the association between student characteristics and mathematical performance; (B) the association between such characteristics and the repetition; (C) the existence of differentiated curricular emphases in Mathematics among Brazilian schools; (D) the meanings attributed to the concepts underlying the PISA conception. The first three objectives deal with statistical regression models. The fourth objective is to understand the policy itself emanated by PISA. It is hoped, therefore, to broaden the curricular debate in the fields of Education and Mathematics Education and to seek a wide understanding on the evaluation policies in Brazilian schools.

Keywords: Assessment policies. Mathematics curriculum. Repetition. Qualitative and Quantitative Approach.

\title{
Introdução
}

As últimas décadas foram marcadas pela criação de sistemas de avaliação da educação em diversos países, incluindo o Brasil. No mundo globalizado do século XXI, chega a ser impossível imaginar um país que não disponha de um sistema avaliativo de suas escolas, ou mesmo de suas universidades. Ao longo desse período, a avaliação vem se tornando sistemática, orgânica e reguladora, ganhando centralidade nas discussões educacionais. Para Nóvoa,

\begin{abstract}
nenhum tema deu origem a tantos estudos e pesquisas. Os investigadores e os especialistas procuraram compreender essa realidade, elaborando instrumentos cada vez mais sofisticados. Os professores basearam grande parte de sua autoridade pedagógica e mesmo de sua identidade profissional no exercício da avaliação. Os decisores políticos colocaramna no centro de suas preocupações. As famílias encararam sempre a avaliação como elemento central da sua ligação com a escola $\left(\mathrm{NÓVOA}^{3}, 2009\right.$, cit. in FERNANDES, 2009, p. 14).
\end{abstract}

Apesar da centralidade da avaliação, em que se ressalta sua importância para o direcionamento de políticas públicas e tomada de decisões, ou mesmo como motivadora dos processos de responsabilização docente, trata-se de um tema bastante polêmico. Para uns, é o caminho único para o alcance da melhoria da qualidade da educação escolar (CASTRO; CARNOY, 2007; WOLFF, 1997).

Wolff (1997, p. 3), por exemplo, afirma que "há um desejo crescente de elevar as expectativas de aprendizado dos estudantes e as avaliações são usadas para determinar se a melhoria pretendida está sendo conseguida". Para outros, contudo, a avaliação é uma forma de poder e de dominação, condutora de um direcionamento à uniformização de discursos, caracterizada,

\footnotetext{
${ }^{3}$ NÓVOA, A. (2009). Prefácio. In: FERNANDES, D. Avaliar para Aprender / Fundamentos, práticas e políticas. (1317). São Paulo: Editora UNESP.
} 
fundamentalmente, em relação aos temas "descentralização, qualidade, competitividade, equidade, reforma curricular, transversalidade, novas tecnologias, dentre outras de caráter mais secundário." (CANDAU, 1999, p. 29).

Nesta vertente, muitas críticas vêm sendo levantadas às formas como as avaliações são conduzidas, às métricas utilizadas para monitorar o desempenho dos estudantes e para avaliar os sistemas educativos. Dentre tais críticas, destacam-se os estudos que evidenciam que as avaliações externas estão pautadas em uma lógica de mercado que justificam práticas meritocráticas, conduzem a uma compreensão estreita e reduzida do sentido de "qualidade", induzem a uma padronização da produção curricular, silenciando as diferenças e conduzindo a um processo de homogeneização nos sistemas educativos (ORTIGÃO; PEREIRA, 2016; TURA; PEREIRA, 2013; FREITAS, 2012; RAVITCH, 2011; FERNANDES, 2009).

Há os que valorizam a avaliação externa pelo mérito de revelar os processos de desigualdades que permeiam os sistemas educativos. Nesse sentido, diversos estudos foram conduzidos com o propósito de buscar compreender a distribuição desigual da educação escolar entre os diversos grupos sociais, culturais e econômicos (FRANCO et al., 2007; CASASSUS, 2007; ORTIGÃO et al., 2007; ORTIGÃO, 2005; ANYON, 1980; COLEMAN, 1988). Há ainda estudos que evidenciam a avaliação externa como um processo social, que precisa ser entendido em toda a sua complexidade, em especial, por possibilitarem às escolas "reflectir sobre as suas práticas numa perspectiva mais alargada.” (VELOSO et al., 2011, p. 85). Para os autores,

a valorização da heterogeneidade dos contextos de aprendizagem e os impactos diferenciados da avaliação nas práticas das escolas poderão implicar uma aferição do modelo de avaliação externa atendendo: à necessidade de uma objectivação de determinados indicadores à permanência mais prolongada nas escolas por parte da equipa de avaliadores, à necessidade de o modelo de avaliação incorporar uma análise do contexto territorial, social e económico das escolas. (VELOSO et al, 2011, p. 85).

O propósito deste texto é o de apresentar algumas reflexões sobre as pesquisas desenvolvidas no âmbito do Grupo de Pesquisa Políticas de Avaliação, Desigualdades e Educação Matemática ${ }^{4}$. O grupo envolve professores universitários, professores da educação básica, estudantes de pós-graduação (nos níveis de Doutorado e de Mestrado) e estudantes de graduação.

A centralidade das investigações está na interpretação e na análise das atuais políticas de avaliação em interface com a discussão curricular. Mais especificamente, o grupo tem se debruçado em análises de microdados e resultados de avaliações externas, tendo em vista a miríade de informações que deles podem ser extraídas e as inferências possíveis de serem realizadas, sempre

\footnotetext{
${ }^{4}$ O grupo de pesquisa é vinculado ao Programa de Pós-Graduação em Educação - ProPEd/Uerj. Foi criado em 2010 com o nome de "Observatório de Periferias Urbanas" e em 2016 adota o novo nome "Políticas de Avaliação, Desigualdades e Educação Matemática”.
} 
em diálogo com a literatura específica. Para tanto, as discussões dos participantes do grupo de pesquisa se apoiam em referências trazidas por Babbie (2005) e Somekh e Lewin (2015), que permitem, em cada estudo, definir a abordagem metodológica, as formas de tratamento, análise e interpretação.

Ao compreender as avaliações externas como políticas educacionais, o grupo tem se apoiado em Stephen Ball (2004, 2005, 2006) e sua articulação com o ciclo de políticas, constituindo um aporte que permite compreender a construção de textos políticos e o fluxo de influências nos diversos contextos de disputa, em relação à política de avaliação, tema bastante caro no momento atual do processo de globalização.

Esse texto está organizado em três seções, além desta introdução. A primeira apresenta um panorama da avaliação no Brasil, descrevendo brevemente o sistema de avaliação brasileiro SAEB/Prova Brasil e o Programa Internacional de Avaliação de Estudantes - PISA. Na sequência, abordam-se os referenciais teórico-metodológicos utilizados nas diversas pesquisas já realizadas e em desenvolvimento, apresentando, por fim, os estudos em andamento e algumas considerações.

\section{Políticas de avaliação da educação no Brasil: SAEB e PISA}

A proposta de institucionalização de um sistema de avaliação da educação brasileira ${ }^{5}$ surgiu durante o período de redemocratização do País (1985-1986), a partir do reconhecimento da inexistência de estudos que mostrassem com clareza o atendimento educacional ofertado à população ${ }^{6}$. O objetivo geral era o de mapear a qualidade dos resultados educacionais, identificando como, quando e quem tem acesso a um ensino de qualidade ${ }^{7}$.

Para Gentili (1995), a mudança de eixo - da democratização da educação para a qualidade da educação - foi acompanhada por "um duplo processo de transposição", caracterizado tanto pelo "deslocamento do problema da democratização ao da qualidade" quanto pela "transferência dos conteúdos que caracterizam a discussão sobre qualidade no campo produtivo-empresarial para o campo das políticas educativas e para a análise dos processos pedagógicos.” (GENTILI, 1995, p. 116).

\footnotetext{
${ }^{5}$ Embora a proposta de instituição de um sistema de avaliação inicie neste período, há registros, na literatura específica, de que já era objeto de interesse na reforma educacional dos anos 1930 e estava presente, desde então, nos esboços de pesquisa e de planejamento educacional.

${ }^{6}$ As décadas anteriores (1960-1980) foram marcadas por uma expansão na oferta de vagas do ensino público brasileiro, que passa de um atendimento de cerca de 40\% (em meados dos anos 1970) para 98\% (nos anos 1990) da população de 7-14 anos de idade. Garantido o acesso, era natural que os governantes passassem a se preocupar com o monitoramento da qualidade educacional.

${ }^{7}$ A proposta inicial está relacionada com demandas do Banco Mundial, a partir da experiência do Projeto Nordeste Segmento Educação, no âmbito do VI Acordo MEC/BIRD, em 1988. Por solicitação das autoridades do Ministério de Educação, visando estender a sistemática de avaliação ao âmbito nacional, esta proposta foi ampliada e, em meados de 1988, foi criado o Sistema Nacional de Avaliação do Ensino Público de $1^{\circ}$ Grau - SAEP.
} 
Segundo o autor, essa transposição trouxe para o campo da educação a necessidade da mensurabilidade, pois "[este] sempre foi o aspecto (central) capaz de materializar qualquer aspiração empresarial que tenda a gerar melhorias nos níveis de qualidade.” (GENTILI, 1995, p. 140).

Uma mudança orientada pela maximização de utilidades e pela necessária adaptabilidade ao mercado, resultando na ideia de qualidade da educação desejável, seria concretizada a partir de um sistema capaz de "medir, comparar e avaliar conhecimentos/padrões de aprendizagem para alcançar a medida/comparação/avaliação de pessoas." (LOPES, 2015, p. 455).

A noção de qualidade, sem dúvida excludente, como uma nova estratégia competitiva invade o campo educacional e marca a construção do sistema de avaliação da educação no Brasil. A primeira experiência, ou primeiro ciclo avaliativo, tem início em 1990 com a criação do Sistema de Avaliação do Ensino Público (SAEP). Quatro anos mais tarde, o INEP amplia a política de avaliação a toda educação básica, com a criação do SAEB - Sistema Nacional de Avaliação da Educação Básica, que passa a avaliar uma amostra de estudantes das séries terminais do ensino fundamental e médio de escolas públicas e particulares em todas as unidades federativas.

Passados doze anos da primeira experiência avaliativa, em 2005 o Governo brasileiro amplia a atuação da avaliação externa com a criação da Prova Brasil, um sistema censitário para avaliar as escolas públicas brasileiras. Com isso, expande-se o alcance dos resultados com informações não apenas para o Brasil e unidades da Federação, mas também para cada município e escola participante. É neste ano também que a avaliação brasileira adota a Teoria da Resposta ao Item $(\mathrm{TRI})^{8}$ como abordagem metodológica na construção e na análise dos instrumentos de coleta de informação - os testes e os questionários. Ao adotar a TRI, a avaliação possibilita comparações entre populações diferenciadas, desde que submetidas a testes que tenham itens em comum (VIANNA, 1987).

Ao longo desses vinte e cinco anos, a avaliação sofreu algumas modificações e, atualmente, se consolidou como um grande sistema que, além do exame por amostragem (ANEB), conta ainda com a Prova Brasil (ANRESC) para avaliar o desempenho em Língua Portuguesa e em Matemática em cada unidade escolar. Além disso, desde o ano de 2007 foi criado o Índice de Desenvolvimento da Educação Básica - IDEB, com a finalidade de monitorar o andamento das políticas públicas pela análise combinada do desempenho dos estudantes nos exames Prova Brasil e SAEB e das taxas de aprovação de cada escola. O IDEB tem sido, desde então, referência para a

\footnotetext{
${ }^{8}$ A TRI consiste em um conjunto de modelos estatísticos que tornam visíveis os traços latentes de um indivíduo, ou seja, as competências cognitivas dos estudantes. De acordo com Valle (2001), o que esta metodologia sugere são algumas formas de representar a relação entre a probabilidade de um aluno responder corretamente a um item e seus traços latentes ou habilidade na área de conhecimento avaliada.
} 
definição de metas a serem alcançadas pelas redes públicas de ensino até 2021. De acordo com Fernandes (2007), um dos idealizadores do IDEB e presidente do INEP no quadriênio 2005-2009, o princípio básico para este indicador é o de que a qualidade da educação envolve que o estudante aprenda e passe de ano.

Esse indicador, contudo, tem recebido muitas críticas, em especial por carregar uma visão restrita do que seja qualidade. Mais ainda, desconsidera uma ideia já consolidada na sociologia da educação de que o desempenho escolar está fortemente associado à origem social do estudante, à organização da escola e das práticas pedagógicas do professor, às condições de infraestrutura física, de trabalho e de violência escolar (FRANCO et al., 2007; SOARES, 2007; ALVES; FRANCO, 2008; SOARES; ALVES, 2013).

Os resultados da Prova Brasil, juntamente com os do IDEB, passaram a ser amplamente divulgados pelo Governo Federal e pelas mídias (por meio de rankings não oficiais) com o intuito de permitir comparações não apenas entre redes, mas entre escolas. Para Bonamino e Souza (2012, p. 380), essa estratégia de divulgação, juntamente com a distribuição nas escolas da matriz de referência utilizada na elaboração dos testes, "introduz perspectivas concretas de interferência mais direta no que as escolas fazem e em como o fazem", um processo que, segundo Ball (2005), tem provocado o aumento da individualização, que inclui a destruição das solidariedades baseadas numa identidade profissional comum.

$\mathrm{Na}$ edição do SAEB 2015, avaliaram-se cerca de 60 mil escolas públicas e aproximadamente duas mil escolas particulares, totalizando quase quatro milhões de estudantes do ensino fundamental e médio testados. Nesta edição houve a incorporação ao SAEB da Avaliação Nacional da Alfabetização (ANA), prevista no Pacto Nacional pela Alfabetização na Idade Certa PNAIC. Outra inovação desta edição foi a inclusão, em caráter experimental, da avaliação de Ciências, realizada com os estudantes do nono ano do ensino fundamental e da terceira série do ensino médio.

Paralelamente à criação do SAEB, o Brasil vem participando, desde 2000, do Programa Internacional de Avaliação de Estudantes - PISA, um programa de educação comparada que avalia uma amostra de estudantes de quinze anos de idade e coordenado internacionalmente pela Organização para Cooperação e Desenvolvimento Econômico (OCDE) e, no Brasil, pelo INEP.

O objetivo dessa avaliação é o de produzir indicadores que contribuam para a discussão da qualidade da educação ministrada nos países participantes, de modo a subsidiar políticas de melhoria da educação. A avaliação procura verificar até que ponto as escolas de cada país participante estão preparando seus jovens ao final da escolaridade básica para a transição à vida adulta. 
Assim como o SAEB, o PISA, além de avaliar as competências dos estudantes nas áreas de conhecimento de interesse do Programa, coleta informações básicas para a elaboração de indicadores contextuais, os quais possibilitam relacionar o desempenho dos estudantes a variáveis socioeconômicas e educacionais. Essas informações são coletadas por meio da aplicação de questionários específicos para os estudantes e para as escolas.

As avaliações do PISA acontecem a cada três anos e abrangem três áreas do conhecimento - Leitura, Matemática e Ciências -, obtendo, a cada edição do Programa, maior ênfase em cada uma dessas áreas. O primeiro ciclo de avaliação ocorreu em 2000 e teve como principal domínio de avaliação a Leitura. Em 2003, o foco foi a Matemática e, em 2006, terceiro ciclo de avaliação, a ênfase foi em Ciências. Uma nova edição do PISA enfatizou Leitura em 2009, Matemática em 2012 e Ciência em 2015.

\section{A avaliação em Matemática na Prova Brasil e no PISA}

Os resultados do SAEB/Prova Brasil e do PISA não são comparáveis entre si. Cada um foi construído de modo a atender a objetivos diferenciados e com base em desenhos específicos, como discutido anteriormente.

O SAEB/Prova Brasil foi desenhado a partir da necessidade de se avaliar a qualidade das escolas e das redes de ensino, além do próprio sistema educacional brasileiro. As provas usadas nessas avaliações são construídas a partir de Matrizes de Referências para a Avaliação. Segundo Ortigão e Sztajn (2001, p. 76), a principal justificativa para a elaboração das Matrizes está na necessidade de se estabelecerem provas a partir de parâmetros consensuais, sejam estes advindos da reflexão teórica sobre a estrutura da ciência e sua correspondente adequação às estruturas de conhecimento, sejam advindos de uma consulta nacional sobre os conteúdos praticados e indicados pelas escolas brasileiras. Assim, segundo as autoras,

os descritores apresentados na Matriz de Matemática assumem o papel de indicar um conjunto de saberes que privilegiam a manifestação da compreensão e do raciocínio dos alunos, a interpretação e produção de diferentes formas de representação, a diversidade de procedimentos, evitando a proposição de aspectos que possibilitem apenas a identificação de conhecimentos memorísticos. (ORTIGÃO; SZTAJN, 2001, p. 77)

Tendo como parâmetro as Matrizes de Referência para a Avaliação (INEP, 2017), os itens que compõem as provas de matemática para o SAEB/Prova Brasil são formulados a partir de situações-problema pautadas em contextos artificiais e escolares. De modo geral, há similaridade entre o que se propõe para a avaliação e o que se pode perceber em livros didáticos avaliados no âmbito do Programa Nacional do Livro Didático (ORTIGÃO, 2005). 
Os desempenhos de estudantes brasileiros em Matemática são dispostos em uma escala contínua, em que os níveis de desempenho são representados pelo número de pontos alcançados. Particularmente a escala de Matemática é subdividida em 13 níveis de proficiência. Nos dois níveis mais baixos da escala (Nível Zero e Nível Um) situam-se os estudantes com pontuação abaixo de 150 e compreendem habilidades simples de resolução de problemas envolvendo soma e subtração de números decimais, cálculo de área com base na contagem das unidades de uma malha quadriculada, multiplicar números de dois dígitos e dividir números de dois dígitos por um número de um algarismo (BRASIL, 2014).

Já no nível mais elevado, Nível 12 da escala, que compreende uma pontuação entre 400 e 425, os estudantes do nono ano do ensino fundamental, dentre outros, são capazes de identificar ângulos retos, reconhecer a expressão algébrica que expressa uma regularidade em sequências numéricas ou de figuras, calcular o diâmetro de circunferências concêntricas e resolver problemas que envolvem equação do segundo grau e grandezas proporcionais (BRASIL, 2014). O gráfico a seguir (Gráfico 1) mostra a distribuição percentual de estudantes brasileiros na escala de proficiência em Matemática da Prova Brasil.

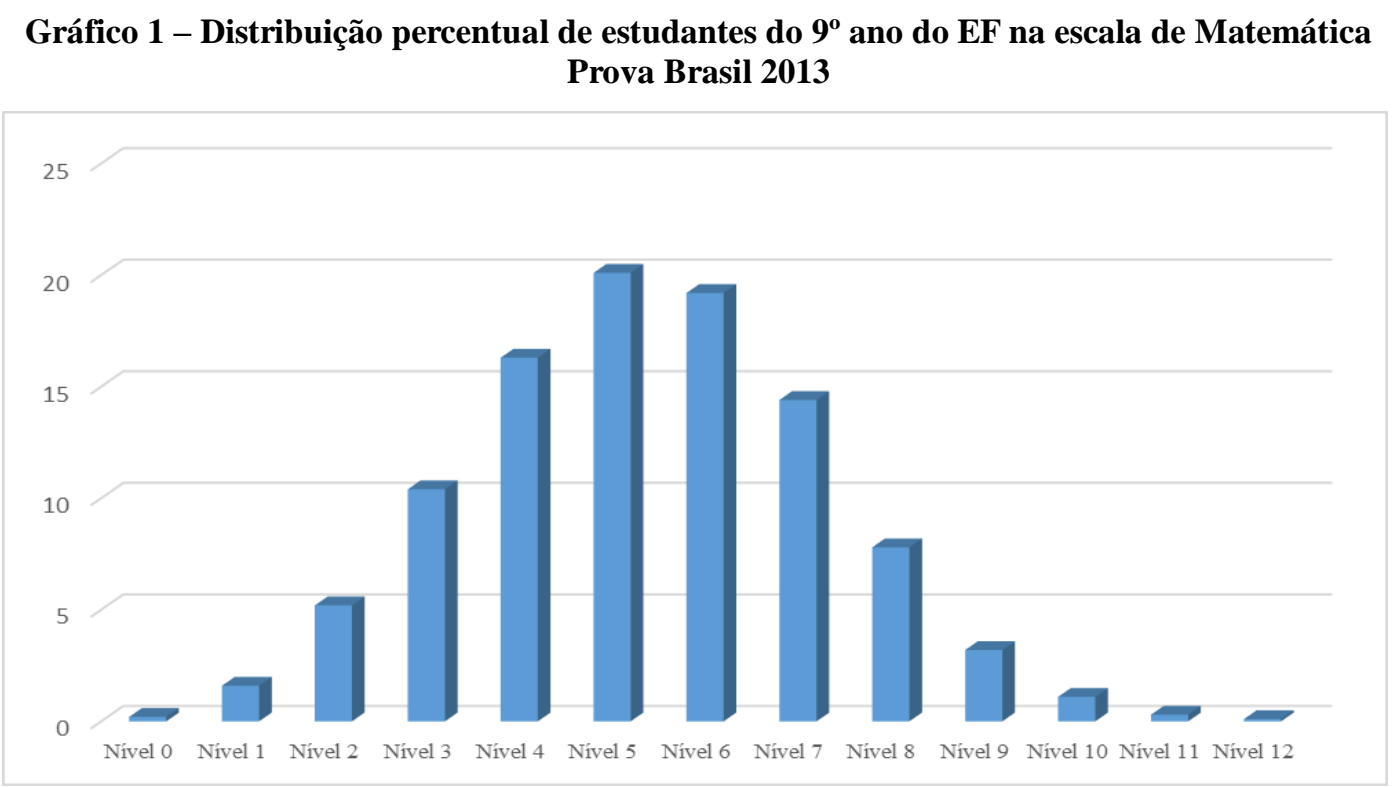

Fonte: INEP. Microdados da Prova Brasil 2013. Elaboração própria.

A análise do gráfico acima evidencia que mais de $80 \%$ dos estudantes estão agrupados entre os níveis três e sete, abaixo, portanto, do que é recomendado no relatório SAEB/Prova Brasil como sendo um nível adequado a estudantes no final do ensino fundamental. O Relatório informa ainda que pouco mais de quinhentos mil estudantes não tiveram sua proficiência calculada por não terem respondido a, no mínimo, três itens de Matemática. 
O PISA é desenhado a partir da ideia de aprendizagem como um processo dinâmico, em que novos conhecimentos e habilidades devem ser continuamente adquiridos, para uma adaptação bem-sucedida em um mundo em constante transformação. Para refletir a amplitude dos conhecimentos, habilidades e competências que estão sendo avaliados, usa-se o conceito de letramento, que remete à

capacidade de um indivíduo identificar e compreender o papel que a Matemática desempenha no mundo real, de fazer julgamentos bem fundamentados e de usar e se envolver na resolução matemática das necessidades de sua vida, enquanto cidadão consciente, construtivo e reflexivo (OCDE, 2013, p. 21).

A noção de letramento adotada pelo PISA relaciona-se com o uso mais abrangente e funcional da Matemática, o que exige do estudante a capacidade de reconhecer e formular problemas matemáticos em variadas situações de sua vida.

Diferentemente de avaliações internacionais anteriores (IEA, TIMMS, OREALC, dentre outras), o PISA não se concentra somente nos conteúdos curriculares, mas enfatiza as competências necessárias à vida moderna. Busca, portanto, verificar a operacionalização de esquemas cognitivos nas diferentes áreas de conhecimento. Em Matemática, o letramento é avaliado em termos de três dimensões:

- o conteúdo de Matemática, definido primeiramente em termos de conceitos matemáticos mais amplos (como estimativa, mudança e crescimento, espaço e forma, raciocínio lógico, incerteza e dependências e relações), e secundariamente em relação a ramos do currículo (como relações numéricas, álgebra, geometria e tratamento da informação);

- o processo da Matemática, definido pelas competências matemáticas gerais. Essas incluem o uso da linguagem matemática, escolha de modelos e procedimentos e habilidades de resolução de problemas. No entanto, a ideia não é separar essas habilidades em diferentes itens de teste, já que se pressupõe que uma série de competências será necessária para desempenhar qualquer tarefa matemática. Essas competências são organizadas em três classes: a primeira consiste na realização de operações simples; a segunda exige o estabelecimento de conexões para resolver problemas; a terceira consiste de raciocínio matemático, generalização e descobertas, e exige que os alunos façam análises, identifiquem elementos matemáticos de uma dada situação e proponham problemas;

- os contextos, compreendidos como as situações nas quais a Matemática é usada, variando de contextos particulares àqueles relacionados com questões científicas e públicas mais amplas.

Para cada dimensão avaliada, existe uma escala contínua, em que os níveis de desempenho dos alunos e o posicionamento destes ao longo da escala estão representados pelo número de pontos alcançados. Particularmente em Matemática, as competências são avaliadas em itens que abrangem 
desde a realização de operações básicas até as habilidades de alta ordem, envolvendo raciocínio e descobertas matemáticas.

Especificamente, estas habilidades são sintetizadas em três grupos: reprodução, conexão e reflexão. O primeiro compreende os processos cognitivos que são requeridos para que o estudante demonstre as habilidades matemáticas que estão ligadas de maneira muito próxima ao que é usualmente entendido como conteúdo. Na maioria das vezes, a solução do item da prova está apoiada em dados e fatos memorizados e na execução de ações repetidas. O segundo, parte do anterior, mas envolve os processos cognitivos exigidos para que o estudante possa demonstrar habilidades relacionadas ao saber-fazer, mesmo que de maneira incipiente. A resolução das tarefas demanda a reunião de ideias para solucionar problemas matemáticos diretos, com maior interpretação da situação. O terceiro desenvolve-se a partir do grupo de conexão, mas abrange habilidades necessárias para a resolução de tarefas que precisam de um pensamento matemático mais amplo, exigindo insight, reflexão e até mesmo criatividade para a resolução do problema.

No PISA os conteúdos matemáticos são organizados em quatro áreas estruturantes, a saber: Quantidade, Espaço e forma, Mudanças e relações, Incerteza. Para os organizadores da avaliação, as três primeiras constituem a essência de qualquer currículo de Matemática da educação básica. A quarta (Incerteza) atende ao caráter mais abrangente da Competência Matemática e se conecta com as necessidades da vida diária do cidadão. O quadro a seguir (Quadro 1) apresenta a escala de habilidades matemáticas (letramento em matemática) no PISA.

Quadro 1 - Níveis de Letramento em Matemática - PISA 2015

\begin{tabular}{|c|l|}
\hline $\begin{array}{c}\text { Nível / } \\
\text { Faixa de } \\
\text { proficiência }\end{array}$ & \multicolumn{1}{c|}{ Letramento em Matemática no PISA } \\
\hline $\begin{array}{c}\text { Abaixo nível 1 } \\
\text { Menor que 358 }\end{array}$ & Não atingiu as habilidades básicas que o PISA objetivava mensurar. \\
\hline $\begin{array}{c}\text { Nível 1 } \\
\text { De 358 a 420 }\end{array}$ & $\begin{array}{l}\text { No nível 1, os estudantes são capazes de responder a questões que envolvem contextos } \\
\text { familiares, em que toda a informação relevante está presente e as questões são claramente } \\
\text { definidas. São capazes de identificar a informação e de executar procedimentos de rotina, de } \\
\text { acordo com instruções diretas, em situações explícitas. Conseguem executar ações que são óbvias } \\
\text { e cujo desenvolvimento parte diretamente dos estímulos dados. }\end{array}$ \\
\hline $\begin{array}{c}\text { Nível 2 } 420 \text { a } 482 \\
\text { De }\end{array}$ & $\begin{array}{l}\text { No nível 2, os estudantes são capazes de interpretar e reconhecer situações em contextos que não } \\
\text { requerem mais do que inferência direta. São capazes de extrair informação relevante de uma } \\
\text { única fonte e fazer uso de um único modelo de representação. Os estudantes conseguem } \\
\text { efetuar raciocínios diretos e de fazer interpretações literais de resultados. }\end{array}$ \\
\hline $\begin{array}{c}\text { Nível 3 } \\
\text { De 482 a 545 }\end{array}$ & $\begin{array}{l}\text { No nível 3, os estudantes são capazes de executar procedimentos descritos com clareza, incluindo } \\
\text { os que requerem decisões sequenciais. Conseguem selecionar e aplicar estratégias simples de } \\
\text { resolução de problemas. Neste nível, os estudantes são capazes de interpretar e usar } \\
\text { representações, com base em diferentes fontes de informação, e de raciocinar diretamente a partir } \\
\text { delas. Conseguem desenvolver comunicações curtas, que relatam os seus resultados, } \\
\text { interpretações e raciocínios. }\end{array}$ \\
\hline
\end{tabular}




\begin{tabular}{|c|c|}
\hline $\begin{array}{c}\text { Nível } 4 \\
\text { De } 545 \text { a } 607\end{array}$ & $\begin{array}{l}\text { No nível 4, os estudantes são capazes de trabalhar eficazmente com modelos explícitos para } \\
\text { situações concretas complexas, as quais podem envolver constrangimentos ou exigir a } \\
\text { formulação de hipóteses. Conseguem selecionar e integrar representações diferentes, } \\
\text { inclusivamente simbólicas, ligando-as diretamente a aspectos de situações da vida real. Neste } \\
\text { nível, os estudantes são capazes de utilizar capacidades bem desenvolvidas e de raciocinar de } \\
\text { modo flexível, com alguma perspicácia (insight), nestes contextos. São capazes de construir e de } \\
\text { comunicar explicações e argumentos com base nos seus argumentos, nas suas interpretações e } \\
\text { ações. }\end{array}$ \\
\hline $\begin{array}{c}\text { Nível } 5 \\
\text { De } 607 \text { a } 669\end{array}$ & $\begin{array}{l}\text { No nível } 5 \text {, os estudantes conseguem desenvolver e trabalhar com modelos de situações } \\
\text { complexas, identificando constrangimentos e especificando hipóteses. São capazes de selecionar, } \\
\text { comparar e avaliar estratégias adequadas de resolução de problemas, para lidarem com problemas } \\
\text { complexos relacionados com estes modelos. Neste nível, os estudantes são capazes de trabalhar } \\
\text { estrategicamente, usando capacidades mentais e de raciocínio amplas e bem desenvolvidas, } \\
\text { representações adequadamente ligadas, caracterizações simbólicas e formais e a perspicácia } \\
\text { (insight) apropriada a estas situações. Conseguem refletir sobre as suas ações e formular e } \\
\text { comunicar as suas interpretações e raciocínios. }\end{array}$ \\
\hline $\begin{array}{c}\text { Nível } 6 \\
\text { Acima de } 669\end{array}$ & $\begin{array}{l}\text { No nível 6, os estudantes são capazes de generalizar e utilizar informação, com base nas suas } \\
\text { investigações e na modelação de situações problemáticas complexas. Conseguem estabelecer a } \\
\text { ligação entre diferentes fontes de informação e diferentes representações e fazer transferências } \\
\text { entre elas, com flexibilidade. Neste nível, os estudantes dispõem de pensamento e raciocínio } \\
\text { matemáticos avançados. Estes estudantes são capazes de aplicar a perspicácia (insight) e a } \\
\text { compreensão, a par do domínio de operações e relações matemáticas simbólicas e formais, no } \\
\text { desenvolvimento de novas abordagens e estratégias em face de situações novas. São capazes de } \\
\text { formular e comunicar com exatidão as suas ações e reflexões no que diz respeito às suas } \\
\text { descobertas, interpretações, argumentos, bem como a adequação dos mesmos às situações } \\
\text { originais. }\end{array}$ \\
\hline
\end{tabular}

Fonte: OCDE/INEP. PISA 2015.

Os resultados dos desempenhos dos estudantes no PISA são fornecidos em uma escala na qual a média dos países da OCDE é padronizada em 500, com 100 de desvio padrão. Isso significa que aproximadamente dois terços dos estudantes participantes obtiveram uma pontuação entre $400 \mathrm{e}$ 600 pontos. Para calcular essa média, considerou-se como se todos os países tivessem mil estudantes participantes, a fim de evitar que a média da OCDE se inclinasse para os países com maior número de estudantes.

No cálculo dessa média, como afirmado anteriormente, o PISA adota a Teoria da Resposta ao Item (TRI) como abordagem metodológica. A tabela a seguir (Tabela 1) apresenta o número de estudantes avaliados e as médias globais obtidas em cada edição do PISA, de 2000 a 2015.

Tabela 1 - Número de participantes e Desempenho médio dos estudantes brasileiros por área de conhecimento, em cada edição do PISA

\begin{tabular}{c|c|c|c|c|c|c}
\hline & PISA 2000 & PISA 2003 & PISA 2006 & PISA 2009 & PISA 2012 & PISA 2015 \\
\hline $\begin{array}{c}\text { Número de alunos } \\
\text { participantes }\end{array}$ & 4.893 & 4.452 & 9.295 & 20.127 & 18.589 & 23.141 \\
\hline Desempenho médio & & & & & & \\
\hline Leitura & 396 & 403 & 393 & 412 & 410 & 407 \\
\hline Matemática & 334 & 356 & 370 & 386 & 391 & 377 \\
\hline Ciências & 375 & 390 & 390 & 405 & 405 & 401 \\
\hline
\end{tabular}

Fonte: OCDE/INEP. PISA. 
Esta tabela evidencia um aumento significativo na quantidade de estudantes de 15 anos testados pelo Programa, em escolas públicas e privadas de todas as regiões geográficas do País. Evidencia ainda que o desempenho médio do Brasil tem melhorado ao longo do tempo. Em Matemática, por exemplo, passamos de uma média de 356, em 2003, para 391, em 2012, e 377, em 2015. Cerca de metade deste aumento, segundo a OCDE (2015), pode ser explicada por mudanças na composição demográfica e socioeconômica da população estudantil. Cerca de $60 \%$ dos estudantes no Brasil têm fraco aproveitamento em Matemática, o que significa que, na melhor das hipóteses, eles podem apresentar explicações matemáticas óbvias e explicitamente evidenciadas. A porcentagem de estudantes compreendida acima do nível basal de proficiência em Matemática aumentou 7,3 pontos percentuais entre 2003 e 2012. Poucos estudantes (0,3\%) no Brasil têm o melhor desempenho em Matemática, o que significa que eles podem identificar, explicar e aplicar o conhecimento matemático e o conhecimento sobre a matemática em uma variedade de situações de vida tidas como complexas.

Até aqui apresentamos o contexto das avaliações que apoiam o desenvolvimento de nossas pesquisas. Como afirmado anteriormente, dois veios de investigações têm nos mobilizado. De um lado, consideramos os microdados gerados pelas avaliações para compreender os resultados obtidos pelos estudantes. Com base nos estudos sociológicos, sabemos que tais resultados são fortemente impactados por características sociais, econômicas e culturais dos estudantes e suas famílias, bem como por características das escolas onde eles estudam. Estes aspectos impõem que análises do processo de escolarização são complexas e precisam considerar não somente os resultados das provas, mas também características pessoais e familiares dos estudantes e as do processo de escolarização. Por outro lado, temos nos debruçado em investigar o próprio texto político das avaliações e os fluxos de influências e disputas nos diversos contextos escolares. Na sequência, apresentamos as nossas pesquisas em cada um desses veios.

\section{Pesquisas que envolvem análise de dados gerados pelas avaliações externas}

No campo da avaliação educacional, esforços têm sido depreendidos no sentido de se compreender que características das práticas educacionais são capazes de explicar os diferentes desempenhos obtidos pelos estudantes. No âmbito do grupo de pesquisa, alguns estudos foram conduzidos por meio do uso dos dados da Prova Brasil e do PISA.

Situam-se nesta perspectiva duas investigações que buscaram compreender características dos estudantes associadas à reprovação escolar, ambas conduzidas por meio da aplicação de modelos de regressão logística (ORTIGÃO; AGUIAR, 2013; ORTIGÃO, AGUILAR JÚNIOR; ZUCULA, 2016). A primeira das investigações fez uso dos dados da Prova Brasil 2009 e a segunda 
utilizou o PISA 2012. Dentre os principais resultados tem-se que a repetência impacta negativamente o desempenho do estudante, atingindo mais os meninos do que as meninas e também os que se autodeclaram pretos em relação a seus colegas (brancos ou pardos). O apoio familiar em relação ao cumprimento das tarefas escolares, ao incentivo em relação aos estudos e à frequência escolar é uma característica que diminui o risco de o estudante ser reprovado.

Também fazendo uso de dados da Prova Brasil, a pesquisa conduzida por um de nós investigou diferenças curriculares entre grupos distintos, mas com mesmas habilidades cognitivas (ORTIGÃO; PEREIRA, 2016). Para isso, fez-se uso de uma abordagem denominada Funcionamento Diferencial do Item (DIF), que possibilita identificar itens que violam um dos principais pressupostos da Teoria da Resposta ao Item (TRI), segundo a qual a probabilidade de acertar um item é função da proficiência do aluno (ANDRIOLA, 2006; SOARES et al., 2005; SOARES, 2005; AGUIAR; ORTIGÃO, 2012; ORTIGÃO, 2014; ORTIGÃO, 2016; ORTIGÃO; PEREIRA, 2016), ou seja, alunos de grupos distintos com igual proficiência têm a mesma probabilidade de acertar um item. Caso isso não ocorra, pode-se afirmar que algum fator que extrapola a habilidade cognitiva do aluno está tornando um item mais fácil para um dos grupos. A análise de DIF permite investigar se um item apresenta ou não grau de dificuldade diferente para subgrupos dentro de uma população que têm, ou deveria ter, o mesmo nível de conhecimento.

No estudo foram analisados 356 itens de matemática, aplicados aos estudantes de $5^{\circ}$ e $9^{\circ}$ anos que participaram da Prova Brasil 2011. Os resultados evidenciaram que os itens não apresentaram DIF entre os grupos considerados. Diante da não presença de DIF, as autoras argumentam que tais resultados podem estar associados tanto à melhoria nos processos teóricometodológicos da avaliação em larga escala como a certa "homogeneização" curricular das escolas públicas brasileiras, que sistematicamente vêm evidenciando pouco avanço no desenvolvimento de habilidades básicas.

Para elas, estudos que evidenciam o pouco avanço dos estudantes das redes públicas municipais e estaduais em relação ao desenvolvimento de habilidades matemáticas (OLIVEIRA, 2015; CÂMARA et al., 2014) fundamentam a primeira hipótese levantada. Tais estudos chamam a atenção para o perigo de uma perspectiva homogeneizadora no currículo de Matemática das redes públicas, na medida em que pouco avanço é verificado no desenvolvimento das habilidades básicas.

Por outro lado, no campo do currículo em geral, têm sido desenvolvidos estudos que destacam o caráter indutor da avaliação em larga escala na produção curricular. Um contexto em que a avaliação ganha centralidade concebida como instrumento capaz de garantir a qualidade da educação sem que haja uma ampla discussão sobre o ideal educacional desejado (FERNANDES; 
NAZARETH, 2011) e em que um Estado regulador promove políticas marcadas por tentativas de normatização e regulamentação do cotidiano das escolas (PEREIRA; VELLOSO, 2012).

Tratam-se, como afirma Ball (2006), de políticas pautadas por uma lógica de mercado "em que valores como competitividade, empreendedorismo e flexibilidade se impõem no lugar de estabilidade, cooperação e justiça social” (FERNANDES; NAZARETH, 2011, p. 64) e justificam as práticas meritocráticas e a produção de rankings entre diferentes instituições sem que as especificidades que as caracterizam sejam necessariamente levadas em conta. A busca pela qualidade que justifica as práticas avaliativas e sustenta os sistemas de avaliação em larga escala tem se limitado à aferição do desempenho dos alunos no desenvolvimento de habilidades arbitrárias e padronizadas (FERNANDES; NAZARETH, 2011). Habilidades que acabam por ser privilegiadas nos currículos, porque essa se torna uma estratégia das escolas para melhorar as suas performances para se inserir na lógica que organiza esse jogo (BALL, 2004). Trata-se de um processo em que as avaliações externas acabam induzindo o currículo. Ou ainda, como afirma Lopes (2015, p. 461), um processo pautado em um "projeto fixado como o melhor para todos, um conhecimento ou uma cultura comum, $[. .$.$] em detrimento da heterogeneidade e da negociação contextual capaz de criar a$ significação de currículo para múltiplos projetos possíveis".

\section{Pesquisas que envolvem o entendimento da política de avaliação}

Para entender as políticas educacionais, especialmente aquelas que focam a avaliação no processo educativo, nosso grupo tem se dedicado a aprofundar o debate sobre a obra de Stephen Ball. Ball (2001, 2004, 2005, 2006) e Ball e Bowe9 (1992, apud MAINARDES, 2006) têm se destacado como referência mundial para compreensão dos impactos da globalização no processo educativo. Apoiando-se nos conceitos de recontextualização de Basil Bernstein (1996, 1998) e na análise do discurso de Foucault (ano), o autor inglês conceitua os ciclos de políticas e os contextos inseridos no processo de construção e profusão de políticas públicas para a educação, utilizando-se, para isso, do processo de recontextualização por hibridização.

De acordo com Ball (2001), mesmo que os produtores de textos de políticas públicas tencionem centralização e controle em tempos de globalização e do livre e fácil acesso às informações e aos textos políticos, a livre circulação destes textos e dos discursos neles contidos e suas interpretações fogem a essa ideia de controle e centralidade, tendo em vista o processo próprio de tradução das políticas públicas.

\footnotetext{
${ }^{9}$ BALL, S.J.; BOWE, R. Subject departments and the "implementation" of National Curriculum policy: an overview of the issues. Journal of Curriculum Studies, London, v. 24, n. 2, p. 97-115, 1992.
} 
Lopes, Cunha e Costa (2013) destacam a influência da proposta de Ball para a compreensão do fluxo e intercâmbio de políticas educativas em níveis locais e globais, sendo hoje referência no Brasil para os estudos pós-coloniais sobre políticas curriculares. Nesse sentido, Lopes, Cunha e Costa (2013, p. 394) afirmam que

a potência da abordagem de Ball encontra-se no reconhecimento de que a circulação dos textos e discursos implica a circulação de ideias, concepções e valores dos atores sociais que atuam no campo da educação e, por isso, produzem a reinterpretação das políticas para além ou para aquém do que é suposto por quem escreve os textos e tenta por eles construir regras para as políticas. Os discursos das políticas atuam de forma coercitiva e tentam não apenas estabelecer os limites do que será lido nos diferentes textos políticos, mas tornar clara - supostamente inconfundível - toda proposta educativa. Às análises que insistem em leituras verticalizadas, desenvolvidas à margem da plasticidade dos textos, da condição enunciativa dos sujeitos, suscitando que as políticas resultam na homogeneização dos contextos, Ball contra-argumenta que há imbricação e permanente tensão entre o local e o global.

Importante também destacarmos como Ball entende o processo de recontextualização por hibridismo nos diversos contextos políticos. Para isso, ele defende que os textos e discursos políticos referentes às políticas educacionais seguem uma trajetória não verticalizada, que se inicia no processo de formulação das políticas públicas até sua implementação no contexto da prática. Dessa forma, Ball e Bowe (1992, apud MAINARDES, 2006, p. 49) traçam três arenas políticas de disputa por hegemonia de discursos que constituem o ciclo de políticas: o contexto de produção de textos - em que se inserem os técnicos e espertos no âmbito governamental responsáveis pela formulação dos textos e das políticas públicas -, o contexto de influência - que seria o papel governamental, através de secretarias de Educação, de implementar as políticas públicas carreadas pelos textos políticos - e o contexto da prática - escolas, colégios, institutos educacionais.

No que se refere ao PISA, dois estudos foram conduzidos com essa perspectiva: um analisa o conteúdo dos itens públicos disponibilizados pelo INEP (LIMA, 2016), à luz das recomendações curriculares e da literatura específica; outro analisa os questionários utilizados pelo Programa, com vias a identificar a permanência de conceitos ao longo das avaliações do PISA (ORTIGÃO; LOS RIOS, 2016).

Respeitando as especificidades dos sistemas de avaliação externa, seja o Prova Brasil ou o PISA, espera-se, a partir das reflexões propostas pelo grupo de pesquisa avaliação educacional, ampliar o debate curricular nos campos da Educação e da Educação Matemática, a fim de ampliar a compreensão sobre as políticas de avaliação das escolas brasileiras, e mostrar que, mesmo que os movimentos conservadores tenham ganhado mais poder, os grupos menos poderosos não se mantiveram passivos (APPLE, BURAS, 2008, p. 24). 


\section{Considerações Finais}

Mostramos aqui um breve panorama de parte das pesquisas desenvolvidas no grupo de pesquisa Políticas de Avaliação, Desigualdades e Educação Matemática. Como base teórico-metodológica, utilizamos os referenciais e os métodos da pesquisa quantitativa e qualitativa discutidos em Babbie (2005) e em Somekh e Lewin (2015), de maneira que possamos construir nossos objetos de pesquisa e estruturar as mais eficazes ferramentas de coleta de dados, bem como refletir sobre os melhores procedimentos para abordagem do problema de pesquisa.

Outro referencial importante em nossos estudos são os trabalhos desenvolvidos por Sthephen Ball (2001, 2004, 2005, 2006), em que revela sua análise profunda do funcionamento e do fluxo dos textos políticos que circulam entre os diversos espaços de disputa por significação de sentidos. Com este referencial, é possível realizar uma descrição dos espaços de construção e de decisão sobre os textos políticos, como também analisar e compreender a circulação e os movimentos de resistência e de disputa para a condução das políticas públicas de avaliação, especialmente no Brasil, que nos últimos anos, em experiências locais e nacionais, implementam sistemas de ensino com centralidade no currículo único e no sistema de avaliação externa.

Pretendemos com este texto apresentar os sistemas de avaliação em larga escala no Brasil, em especial o SAEB e o PISA, discorrendo sobre suas características e sua construção ao longo do tempo, e seus possíveis impactos na construção e direcionamento de políticas de avaliação, impactando diretamente nas políticas públicas em Educação, alargando nossa compreensão sobre o tema e suscitando novos debates acerca das políticas de avaliação no Brasil.

Nosso foco recai, também, nos instrumentos de avaliação da disciplina Matemática e entendemos que se trata de um novo campo da Educação Matemática a ser explorado e investigado. Nesse sentido e encerrando este texto, destaca-se aqui um breve panorama de parte das pesquisas desenvolvidas no grupo de pesquisa Políticas de Avaliação, Desigualdades e Educação Matemática. Em especial, aqui enfatizamos aquelas que se situam no campo da Educação Matemática. Além dessas, contudo, pelo fato de o grupo estar vinculado a um Programa de Pós-graduação em Educação, suas pesquisas abarcam temáticas fora desse campo. São elas:

- Investigação sobre as práticas curriculares/avaliativas no curso de Pedagogia da Universidade do Estado do Piauí, no que se refere à constituição teórico-prática de seus elementos curriculares. Trata-se de pesquisa de doutorado desenvolvida por Antónia Alves Pereira Silva, com auxílio da FAPESPI.

- Investigação sobre percepção de professores em formação, sobre direitos humanos. Para esta pesquisa, um questionário está sendo construído, com base em Earl Babbie (2005), com vias a compreender como estudantes do Curso de Pedagogia do CEDERJ percebem os direitos 
humanos e como incorporam tais percepções em suas práticas como professores. Trata-se de pesquisa de doutorado desenvolvida por Guilherme Pereira, com auxílio da FAPERJ.

Dada a diversidade dos percursos formativos de seus membros e as primeiras aproximações com a temática, concluímos, destacando que esse é o desafio do nosso grupo de pesquisa na condução das investigações aqui apresentadas. De fato, verificamos, nos estudos realizados, a potência das leituras sobre políticas curriculares e de avaliação para a formulação de nossas temáticas de pesquisa, que toma o campo da Avaliação como espaço de produção de conhecimento em potencial, aproximando-nos, também, das contribuições de métodos quantitativos e qualitativos de pesquisas, na busca de respostas às nossas questões de investigação.

\section{Referências}

AGUIAR, G..; ORTIGÃO, M. I. R. Letramento em Matemática: um estudo a partir dos dados do PISA 2003. Boletim de Educação Matemática - BOLEMA (UNESP. Rio Claro. Impresso), 26, p. 01-21, 2012.

ANYON, J. Social class and the hidden curriculum at work. Journal of Education, 162(1), p. 67-92, 1980.

ALVES, M. T. G., FRANCO, C. A pesquisa em eficácia escolar no Brasil: evidências sobre o efeito das escolas e fatores associados à eficácia escolar. In: BROOKE, Nigel; SOARES, José Francisco. (Orgs.) Pesquisa em eficácia escolar: origem e trajetórias. Belo Horizonte: UFMG, 2008.

ALVES, F.; ORTIGÃO, M. I. R.; FRANCO, C. Origem social e risco de repetência: interação entre raça-capital econômico. Cadernos de Pesquisa. São Paulo: Fundação Carlos Chagas/Autores Associados, v. 37, n. 130, p. 161-180, 2007.

ANDRIOLA, W. B. Estudo sobre o viés de itens em testes de rendimento: uma retrospectiva. Estudos em Avaliação Educacional, 17(35), pp. 115-134, 2006. Disponível em http://www.fcc.org.br/pesquisa//publicacoes/eae/1342/1342/pdf. Acesso em 23 out. 2016.

APPLE, Michael W. Currículo, poder e lutas: com a palavra, os subalternos/Michael W. Appe, Kristen L. Buras; tradução Ronaldo Cataldo Costa. Porto Alegre: Artmed, 2008.

BABBIE, E. Métodos de pesquisas de survey. Belo Horizonte: UFMG, 2005.

BALL, S. Diretrizes Políticas Globais e Relações Políticas Locais em Educação. CURRÍCULO SEM FRONTEIRAS. v. 1, n. 2, p. 99-116, 2001. Disponível em http://www.curriculosemfronteiras.org/vol1iss2articles/ball.pdf. Acesso em 03 nov. 2016.

. Performativities and Fabrications in the Educational Economy: towards the performative society. In Stephen J. Ball, (Ed.). THE ROUTLEDGE FALMER READER IN SOCIOLOGY OF EDUCATION. London: Routledge Falmer, pp. 143-155, 2004.

. Profissionalismo, gerencialismo e performatividade. Cadernos de Pesquisa. São Paulo: 35(126), p. 539-564, 2005. Disponível em http://www.scielo.br/pdf/cp/v35n126/a02n126.pdf. Acesso em 23 out. 2016.

. Sociologia das políticas educacionais e pesquisa crítico-social: uma revisão pessoal das políticas educacionais e da pesquisa em política educacional. Currículo sem fronteiras. São Paulo: 6(2), pp. 10-32, 2006. Disponível em

http://www.curriculosemfronteiras.org/vol6iss2articles/ball.pdf. Acesso em 23 out. 2016. 
BERNSTEIN, B. A Estruturação do Discurso Pedagógico: Classe, Códigos e Controle. Petrópolis: Vozes, 1996.

. Pedagogía, control simbólico e identidad. Madrid: Morata, 1998.

BRASIL. MEC/INEP. SAEB/ PROVA BRASIL 2013 - primeiros resultados. Disponível em: http://download.inep.gov.br/educacao_basica/prova_brasil_saeb/resultados/2013/Saeb_2013_primei ros_resultados_site_Inep.pdf. Acesso em 10 fev. 2017.

CÂMARA, M., ORTIGÃO, M. I. R., AGUIAR, G. Saberes docentes versus saberes discentes: Convergências e divergências. Relatório Técnico. Edital Projetos de pesquisa e desenvolvimento de instrumentos de avaliação de competências para a educação básica. Convênio CAED/PUC-Rio, 2014. (Manuscrito não publicado.)

CANDAU, V. M. (org.). Magistério: construção cotidiana. 3ª ed., Petrópolis: Vozes, 1999.

CASASSUS, J. A escola e a desigualdade (Tradução Lia Zatz). 2a ed. Brasília: Líber Livro, Unesco, 2007.

CASTRO, C. M.; CARNOY, M. Como anda a reforma da educação na América Latina? Rio de Janeiro: FGV, 1997.

COLEMAN, J. S. (1988) Social capital in the creation of human capital. American Journal of Sociology, v. 94, p. S95-S120.

FERNANDES, R. Índice de Desenvolvimento da Educação Básica (IDEB): metas intermediárias para a sua trajetória no Brasil, estados, municípios e escolas. Instituto Nacional de Estudos e Pesquisas Educacionais ‘Anísio Teixeira' - INEP Ministério da Educação - MEC, 2007.

Disponível em

http://download.inep.gov.br/educacao_basica/prova_brasil_saeb/menu_do_professor/o_ideb/Ideb_P rojecoes.pdf. Acesso em 23 jan. 2017.

FERNANDES, D. Avaliar para aprender: fundamentos, práticas e políticas. São Paulo: UNESP, 2009.

FERNANDES, C. O., NAZARETH, H. D. G.. A retórica por uma educação de qualidade e a avaliação de larga escala. Impulso. 21(51), p. 63-71, 2011. Disponível em:

http://www.metodista.br/revistas/revistas-nimep/index.php/impulso/article/viewFile/526/550. Acesso em 15 jan. 2017.

FRANCO, C.; ORTIGÃO, M. I. R.; BONAMINO, A. Eficácia escolar em Brasil: investigando prácticas y políticas escolares moderadoras de desigualdades educacionales. In: CUETO, S.

Educación y brechas de equidad em América Latina. Santiago: Fondo de Investigaciones Educativas / PREAL, Tomo I, p. 223-249, 2007.

FREITAS, L. C. Os reformadores empresariais da educação: Da desmoralização do magistério à destruição do sistema público de educação. Educação \& Sociedade, 119, p. 379-404, 2012. Disponível em http://www.scielo. br/pdf/es/v33n119/a04v33n119.pdf. Acesso em 14 jan. 2017.

GENTILI, P. O discurso da qualidade como nova retórica conservadora no campo educacional. (pp. 111-177). In Pablo Gentili e Tomaz Tadeu da Silva (Orgs.), Neoliberalismo, qualidade total e educação: Visões críticas. Petrópolis: Vozes, 1995.

LIMA, R. L. Avaliação em Geometria no PISA 2012: uma análise dos conteúdos e dos resultados dos itens disponibilizados pelo INEP. 92f. (Dissertação de Mestrado. Universidade do Estado do Rio de Janeiro. Programa de Pós-graduação em Educação, Cultura e Comunicação em Periferias Urbanas. Duque de Caxias-RJ), 2016. 
LOPES, A. C. Por um currículo sem fundamentos. Linhas Críticas - Revista da Faculdade de Educação - UnB. V. 21, nº 45, p. 445-466, 2015. Disponível em http://periodicos.unb.br/index.php/linhascriticas/article/view/16735/11881. Acesso em 3 jan. 2017.

LOPES, A. C.; CUNHA, E. V. R.; COSTA, H. H. C. Da Recontextualização à Tradução: investigando políticas de currículo. Currículo sem fronteiras, São Paulo: v. 13, n.3, p. 392-410, 2013.

MAINARDES, J. Abordagem do Ciclo de Políticas: uma contribuição para a análise de políticas educacionais. Educação e sociedade. Campinas: v. 27, n. 94, p. 47-69, 2006. Disponível em http://www.scielo.br/pdf/es/v27n94/a03v27n94.pdf. Acesso em 03 nov. 2016.

OLIVEIRA, A. S. Um olhar sobre a Prova Brasil: análise dos resultados em matemática (Dissertação de mestrado). Faculdade de Educação da Baixada Fluminense, Universidade do Estado do Rio de Janeiro, Duque de Caxias, Brasil. 2015.

ORGANIZATION FOR ECONOMIC CO-OPERATION AND DEVELOPMENT - OCDE. What Students Know and Can Do: Student Performance in Mathematics, Reading and Science, summarises the performance of students in PISA 2012. Paris: Organization for Economic CoOperation and Development, 2013.

ORTIGÃO, M. I. R.; PEREIRA, T. V. Homogeneização curricular e o sistema de avaliação nacional brasileiro: o caso do estado do Rio de Janeiro. EDUCAÇÃO, SOCIEDADE \& CULTURA. São Paulo: $n^{\circ} 47$ (1). Dossiê Temático: A Avaliação das Escolas: Políticas, Perspectivas e Práticas, pp. 157-173, 2016. Disponível em: http://www.fpce.up.pt/ciie/sites/default/files/ESC47Isabel.pdf. Acesso em 12 nov. 2016.

ORTIGÃO, M. I. R.; ZUCULA, A. F.; AGUILAR JÚNIOR, C. A. Analisando a repetência escolar a partir de dados do PISA 2012. In: VI Simpósio Internacional de Educação Matemática - VI SIPEM. 15 a 19 de novembro, Pirenópolis (GO), 2015. Disponível em http://www.sbembrasil.org.br/visipem/anais/story_content/external_files/ANALISANDO\%20A\%2 0REPET\%C3\%8ANCIA\%20ESCOLAR\%20A\%20PARTIR\%20DOS\%20DADOS\%20DO\%20PIS A\%202012.pdf. Acesso em 27 set. 2016.

ORTIGÃO, M. I. R. Estudo do Funcionamento Diferencial do Item em um instrumento de avaliação do desempenho em matemática. In: FRANGELLA, Rita de Cassia Prazeres (Org.). Currículo, Formação e Avaliação: redes de pesquisas em negociação. Curitiba: CRV, 2016, pp. 67-82.

ORTIGÃO, M. I. R; LOS RIOS, M. B. C. H. O. de. Avaliação e currículo de Matemática: um olhar sobre o PISA. FAPERJ: Projeto de Iniciação Científica, 2016.

ORTIGÃO, M. I. R. Estudo comparativo entre escolas situadas em periferias e em capitais brasileiras sobre ênfases curriculares em matemática, a partir da análise do comportamento diferencial do item (DIF) na Prova Brasil. Relatório Técnico: Prociência. Universidade do Estado do Rio de Janeiro (Apoio Programa Jovem Cientista do Nosso Estado 2011 / FAPERJ), 2014.

ORTIGÃO, M. I. R.; FRANCO, C.; CARVALHO, J. B. P. A distribuição social do currículo de matemática: quem tem acesso a tratamento da informação? Educação Matemática Pesquisa, São Paulo, v. 9. n. 2, p. 249-273, 2007.

ORTIGÃO, M. I. R.; SZTAJN, P. Dilemas para a Avaliação: o caso dos conjuntos no ensino da matemática. In: FRANCO, C. (Org.). Avaliação, Ciclos e Promoção na Educação. Porto Alegre: Artmed. pp. 69-84, 2001.

P, T. V.; VELLOSO, L. Um salto para a performatividade: sentidos atribuídos à qualidade da educação. Ensaio: Avaliação e Políticas Públicas em Educação. № 20(74), p. 73-88, 2012. Disponível em: http:// www.redalyc.org/articulo.oa?id=399538140005. Acesso em 15 dez. 2016. 
PISA 2012. Questionário do aluno - Modelo A. Brasil. INEP. Programa Internacional de Avaliação de Estudantes 2012 - OECD. Disponível em: http://portal.inep.gov.br/. Acesso em 08 dez. 2013.

RAVITCH, D. Vida e morte do grande sistema escolar americano: como os testes padronizados e o modelo de mercado ameaçam a educação. Porto Alegre: Sulina, 2011.

SOARES, J. F. Qualidade e equidade na educação brasileira: fatos e possibilidades. In: BROOKE, N.; SCHWARTMAN, S. Os desafios da educação no Brasil. Rio de Janeiro: Nova Fronteira, pp. 91-117, 2005.

SOARES, T. M.; GENOVEZ, S. F. M.; GALVÃO, A. F. Análise do Comportamento Diferencial dos Itens de Geografia: estudo da $4^{\mathrm{a}}$ série avaliada no Proeb/Simave 2001. Estudos em avaliação educacional, São Paulo, 16(32), pp. 481-493, 2005. Disponível em http://www.din.uem.br/sbpo/sbpo2005/pdf/arq0197.pdf. Acesso em 10 out. 2016.

SOARES, J. F. Melhoria do desempenho cognitivo dos alunos do ensino fundamental. Cadernos de Pesquisa, São Paulo, v. 37, n. 130, p. 135-160, 2007. Disponível em: < http://www.scielo.br/pdf/cp/v37n130/07.pdf >. Acesso em 23 jan. 2017.

SOARES, J. F.; ALVES, M. T. G. Escolas de ensino fundamental Contextualização dos resultados. Revista Retratos da Escola. Brasília, v. 7, n. 12, pp. 145-158, jan./jun., 2013. Disponível em: http://www.esforce.org.br/index.php/semestral/article/viewFile/268/445. Acesso em 20 nov. 2016.

SOMEKH, B.; LEWIN, C. (Orgs). Teoria e Métodos de Pesquisa Social. Petrópolis: Vozes, 2015.

TURA, M. L. R.; PEREIRA, T. V. Políticas curriculares, sistemas de avaliação e conhecimentos escolares. In Maria de Lourdes R. Tura \& Maria Malta A. Garcia (Org.), Currículo, políticas e ação docente (pp. 111-125). Rio de Janeiro: EdUERJ, 2013.

WOLFF, L. Avaliações educacionais: uma atualização a partir de 1991 e implicações para a América Latina. In: BOMENY, H. (Org.). Avaliação e determinação de padrões na educação latino-americana. p. 1-8, Rio de Janeiro: Fundação Getúlio Vargas, 1997.

VELOSO, L.; ABRANTES, P.; CRAVEIRO, D. A avaliação externa de escolas como processo social. Educação, Sociedade \& Culturas, nº 33, p. 69-88, 2011. Disponível em http://www.fpce.up.pt/ciie/revistaesc/ESC33/ESC33_Artigos_Veloso.pdf. Acesso em 15 jan. 2017.

VIANNA, H. M. Testes em educação. São Paulo: IBRASA, 1987.

Submetido em janeiro de 2017

Aprovado em março de 2017 